\section{Effects of gap size and within-gap position on seedlings establishment in silver fir stands}

\begin{abstract}
Albanesi E, Gugliotta OI, Mercurio I, Mercurio R*
Abstract: The conversion of pure conifer plantations into stands with heterogeneous structure and composition is a current silvicultural challenge in Italy. A silvicultural system aiming to the regeneration of natural forests by means of openings in the canopy cover is considered. The purposes of this study are: I) to evaluate if the creation of gaps is an appropriate way to transform homogeneous man-made stands of silver fir (Abies alba Mill.) into naturally regenerated stands; II) to analyse the influence of micro-environmental conditions in gaps of different size on the recruitment and establishment of natural regeneration of forest tree species. After three growing seasons silver fir seedlings recruitment was greater in small gaps and in the central-southern positions where PAR was lower and the shading influence of ground vegetation less relevant. The most suitable gap size for silver fir regeneration, in the southern Apennine, is $200(300) \mathrm{m}^{2}, \mathrm{D} / \mathrm{H}=0.5$ and anyway $<0.75$. The silvicultural treatment proposed seems to foster natural regeneration of silver fir and other broadleaves, enhancing the development of a multi-layered forest structure and fulfilling timber production objectives without compromising ecosystem management principles.
\end{abstract}

Keywords: forest gaps, light, natural regeneration, silvicultural systems, Abies alba, Italy

\section{Introduction}

Silver fir (Abies alba Mill.) was artificially spread in many areas of Apennines since XIV century. Later on, a lack of attention to the forest management, tree ageing processes, insects and fungi outbreaks lead to an unsteady biological equilibrium in many plantations. The conversion of conifer plantations into stands with heterogeneous structure and composition is a current challenge for Italian silviculture. A silvicultural system aiming to the natural regeneration by means of canopy gaps is here considered.

Watt (1947) first recognized the importance of gaps in ecological regeneration. Treefall gap disturbances are important to the species dynamics of many forest types (Pickett \& White 1985, Platt \& Strong 1989). In addition, gaps are important in maintaining and enhancing biological diversity (Fenner 1985, Denslow 1987, Whit-

Dipartimento di Gestione dei Sistemi, Agrari e Forestali, Università Mediterranea, Località Feo di Vito - 89100 Reggio Calabria (Italy)

${ }^{*}$ Corresponding Author: Roberto Mercurio (rmercurio@unirc.it).

Citation: Albanesi E, Gugliotta OI, Mercurio I, Mercurio R, 2008. Effects of gap size and within-gap position on seedlings

establishment in silver fir stands. iForest 1: 55-59 [online: Feb 28, 2008] URL:

http://www.sisef.it/iforest/ more 1989, Brokaw \& Scheiner 1989, Poulson \& Platt 1989, Busing \& White 1997, Coates \& Burton 1997, Gray et al. 2002).

This approach meets the requirement of a forest management aiming to low environmental impact in accordance with the principles of sustainable silviculture, biodiversity conservation and the concepts of "the silviculture of transformation” (O'Hara 2001).

Coates \& Burton (1997) review the gap dynamics literature with special attention to the use of gap size or position as predictive variables for silvicultural success or maintenance of ecosystem function. The role of gap size and within-gap position on the establishment of tree species has been studied in many different managed forests (Gray \& Spies 1996, Van Der Meer et al. 1999, Coates 2000, Malcom et al. 2001, Diaci 2002, Gagnon et al. 2003, Zhu et al. 2003).

The purposes of this study are: 1) to assess if the opening of gaps is an appropriate tool to transform man-made pure stands of Abies alba into naturally regenerated stands; 2) to analyse the influence of micro-environmental conditions in different gap size on the recruitment and establishment of natural regeneration of forest tree species three years after gaps opening.

\section{Materials and Methods}

The study area was located in artificial silver fir (Abies alba Mill.) stands on the north aspect of Serra S. Bruno (VV - Calabrian
Apennine: $\left.38^{\circ} 33^{\prime} \mathrm{N} ; 1^{\circ} 19^{\prime} \mathrm{E}\right)$ at $900-940 \mathrm{~m}$ a.s.l., with an inclination of $5 \%$.

Mean annual precipitations are $1848 \mathrm{~mm}$, summer precipitations are $102 \mathrm{~mm}$, with a dry period of 46 days, air humidity is normally high and never falls below $60 \%$. Mean annual temperature is $10.8^{\circ} \mathrm{C}$, mean temperature of the coldest month is $3.1{ }^{\circ} \mathrm{C}$, mean temperature of the warmest month is 21.5 ${ }^{\circ} \mathrm{C}$. Soils classified as Humic Dystrudept (USDA 1998), are acid, deep, well drained and derived from granitic parent material. The natural forest vegetation is dominated by silver fir-beech stands (Aquifolio- $\mathrm{Fa}$ getum Gentile 1969 - Barbagallo et al. 1982) with sparse plants of chestnut (Castanea sativa Mill.).

During the late summer 2001 two sizes of circular gaps were created by cutting and removing all trees in a 90 year old stand, considering small $\left(185 \mathrm{~m}^{2}\right)$ and medium (410 $\mathrm{m}^{2}$ ) gaps with three replicates of each size. The gap diameter (measured between stems edges) to the tree height ratios were respectively 0.50 and 0.75 (mean stand height 30.5 $\mathrm{m})$.

Thirteen circular subplots of $3.14 \mathrm{~m}^{2}(100$ $\mathrm{cm}$ radius) were established inside each gap. Subplots were positioned one in the central part of the gap and the others along the cardinal directions. Starting from the centre each subplot was placed at one third of the radius.

The percent of vegetation cover was estimated in each subplot and in the whole gap. We considered all the seedlings born after the canopy opening. Each of these seedlings was identified by species, total height was measured and the age was visually determined. Census of seedlings in each subplot was conducted at the end of each growing season. Seedlings mortality was calculated as a difference between the inventories taken in the years 2002, 2003 and 2004.

To follow the seedlings growth in different gap micro-environments, 10 seedlings were marked with small pin flags in each sub-plot and total height of each seedling was recorded at the beginning (May) and at the end (October) of growing season 2003 and 2004. Seedling height increments were calculated over the course of growing season.

Four soil cores $(8 \mathrm{~cm}$ diameter $\times 15 \mathrm{~cm}$ depth) were taken, every month, in the central part and four in the edge of each gap to assess the soil moisture content with gravimetric method. Four core samplings were collected also below the stand adjacent to the gaps to assess the microclimatic conditions under closed forest (control).

Only one depth level of sampling was chosen as seedlings concentrate the greatest part of their root system in the superficial layers of the soil. The soil samples were 
weighed immediately after the collection (wet weight). Later, in the laboratory, soil samples were dried in a drying oven at $105 \pm$ $2{ }^{\circ} \mathrm{C}$ to constant weight and reweighed (dry weight).

Soil moisture content was expressed as percentage of dry weight:

$$
q=(w w-d w) / d w \cdot 100
$$

Measurements of the Photosynthetically Active Radiation (PAR - radiation in the 0.4$0.7 \mu \mathrm{m}$ waveband) were collected with a ceptometer (AccuPAR, Degagon Devices Inc., Pullman, WA, USA - Pierce \& Running 1988 ), at $1.00 \mathrm{~m}$ above the ground, with the instrument held horizontally. Four instantaneous readings were done at each sampling point, with reference to the cardinal directions.

These measurements were carried out monthly, during growing season (MaySeptember), in bright sunny days, at 12.00 (local solar time). Measurements were taken: - in the full open, in a large clearing near the experimental area

- inside the adjacent stands

- in correspondence of each subplot.

After each measurement cycle for each sampling point the PAR transmittance was calculated using the following formula:

$$
P A R_{\text {transmittance }}=\left(\frac{P A R_{\text {subplot }}}{P A R_{\text {full open }}}\right) \cdot 100
$$

Data were grouped for analysis according to the position of the subplot inside the gap: GAP CENTRE (C,1N,1E,1S,1W) central subplot plus the four nearest subplots in the cardinal directions and GAP EDGE $(2 \mathrm{~N}, 2 \mathrm{E}, 2 \mathrm{~S}, 2 \mathrm{~W}, 3 \mathrm{~N}, 3 \mathrm{E}, 3 \mathrm{~S}, 3 \mathrm{~W})$ the others.

Specific leaf area (SLA, leaf area per unit of leaf dry weight) was calculated for 12 silver fir seedlings at the end of the third growing season in gap centre and gap edge. Silver fir current-year needles were sampled, bagged in plastic, refrigerated and returned to the laboratory. Total leaf area (one-sided) per seedling was measured with an area meter (LI 3100, LI-COR Inc. Lincoln, NE, USA) and needles were weighed after drying for 24 hours at $85 \pm 2{ }^{\circ} \mathrm{C}$.

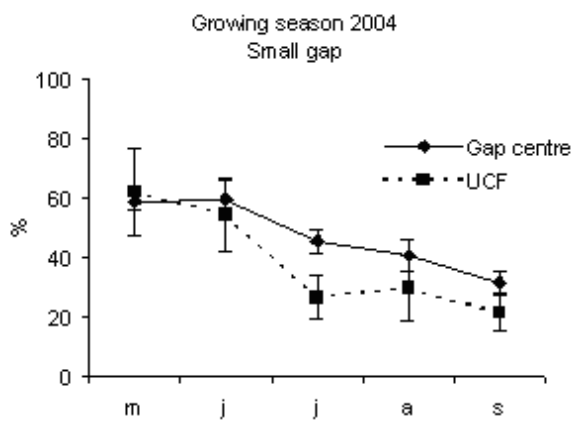

Differences in soil moisture, PAR transmittance, seedling density, seedling mortality, height increment and SLA were compared by means of a paired samples $t$ - test $(p<0.05)$ between gap sizes and within-gap position (Statistica, Statsoft ${ }^{\mathbb{Q}}$, Inc. Tulsa, OK, USA).

\section{Results and discussion}

\section{Soil moisture}

Soil moisture levels were not different between gap sizes and specifically both between gap centres and between gap edges (Fig. 1).

In all gaps soil moisture content was higher in the gap centre than in the gap edge with significant differences (Fig. 1). These findings are in accordance with Gray et al. (2002) in gap sizes that ranged from 40 to $2000 \mathrm{~m}^{2}$ in mature Douglas-fir forests in the Pacific Northwest (USA). In a different way, according to the studies of McGuire et al. (2001) and Gagnon et al. (2003) in Pinus palustris stands in Florida and Georgia (USA), soil moisture did not vary from the gap edge to gap centre when drought conditions prevailed. Soil moisture was higher inside the gaps if compared with those recorded under closed forest (Fig. 2 and Fig. 3) with significant differences between small gaps and surrounding closed forest. This confirms the observations by Gray et al. (2002) in gaps in mature Douglas-fir forests in the Pacific Northwest (USA); by Cutini et al. (2004) in gaps in silver fir stands in Central Apennines (Italy) and by Ritter et al. (2005) in gaps of beech-dominated forest in Denmark. Soil water values are higher in the gaps than in the surrounding forest probably in relation to both an increase in precipitation and a decrease in transpiration in the gaps (Zirlewagen \& von Wilpert 2001, Zhu et al. 2003).

\section{PAR transmittance}

PAR transmittance was higher in medium gaps than in small ones (Fig. 4) with significant differences between gap sizes.

These findings confirm that the amount of light received on the ground in a forest canopy gap is directly related to the size of the



Fig. 3 - Monthly soil moisture content in gap centre and under closed forest (UCF). The vertical bars represent standard errors. canopy opening (Canham et al. 1990, Lieffers et al. 1999, McGuire et al. 2001, Diaci 2002, Gray et al. 2002).

PAR transmittance varied within-gap position, as observed by Canham et al. (1990), Brown (1996), McGuire et al. (2001), Diaci (2002), Gagnon et al. (2003). High values were recorded in gap centre rather than in gap edge (mainly in medium gap) but without significant differences (Fig. 4) and decrease from north to centre and to south positions for all gap sizes (Fig. 5). This is in accordance with Gray et al. (2002) in experimental gaps in old-growth forests and mature forests dominated by P.menziesii and $T$. heterophylla in the Cascade Mountains (USA) where the gap diameter to tree high ratios were 0.2, 0.4, 0.6 and 1.0. Gagnon et al. (2003) for a $3000 \mathrm{~m}^{2}$ experimental gap in Pinus palustris stands of Florida (USA)

Growing season 2004

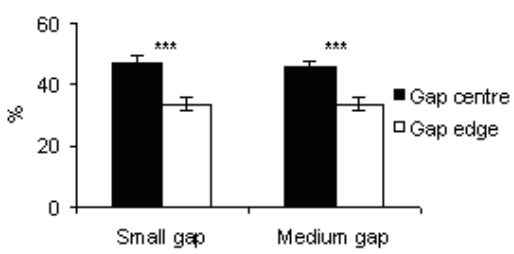

Fig. 1 - Means ( \pm s.e.) of soil moisture content among gap sizes and within-gap position.

Growing season 2004

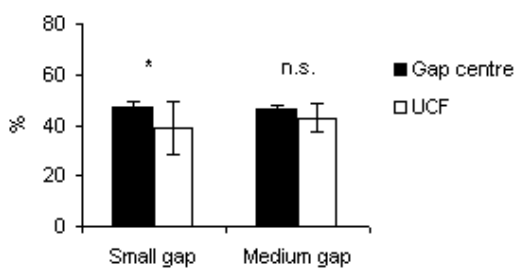

Fig. 2 - Means ( \pm s.e.) of soil moisture content among gap sizes and among gap centre and under closed forest (UCF)

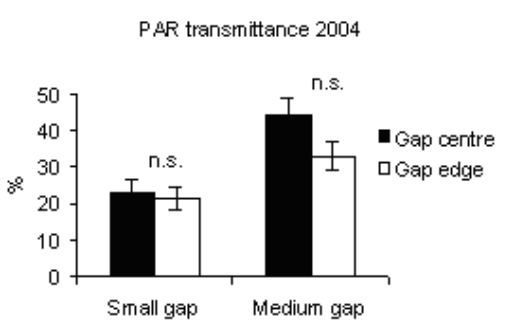

Fig. 4 - Means ( \pm s.e.) of PAR transmittance (h 12.00) according to gap sizes and withingap position. 

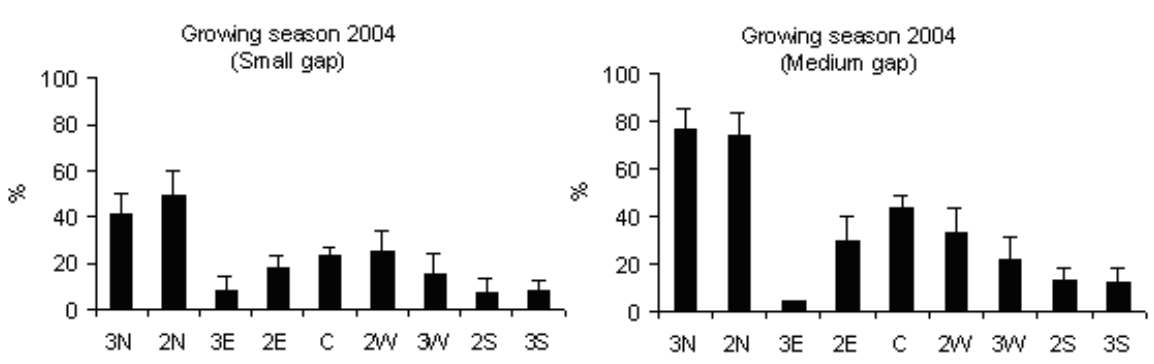

Fig. 5 - Distribution of PAR transmittance (h 12.00) according to within-gap position. The vertical bars represent standard errors.
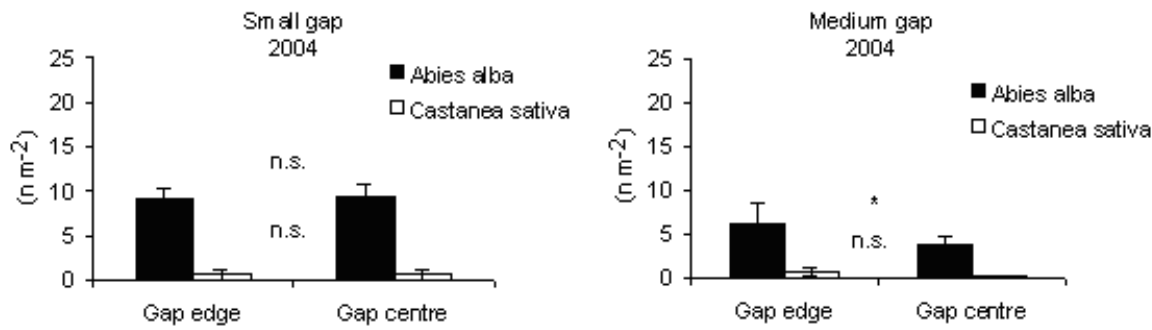

Fig. 6 - Means ( \pm s.e.) of distribution of seedlings density according to gap sizes and withingap position.

found that PAR transmittance was higher in the gap centre and lower near the gap edge and also between the northern and southern zones. Meanwhile, the difference in light between north and south aspects of gaps was attenuated as gap size increased (Coates 2000, McGuire et al. 2001).

Lower $\mathrm{T}_{\mathrm{PAR}}$ values recorded in the subplots in south zone compared to those in north zone can be explained as a consequence of the slope aspect and inclination effect and the influence of surrounding trees in gap edges.

The light levels beneath closed-canopy forests were $1 \%$ of full sunlight, as reported $(<1-2 \%)$ by Canham et al. (1990) in many forest types. This could explain the deficiency of natural regeneration. In fact values $<2 \%$ of PAR transmittance represent the threshold of silver fir seedlings survival (Magini 1967, Paci 2004, Hunziker \& Brang 2005).

\section{Seedling density}

Silver fir (the most abundant species with respect to chestnut) seedling density was higher in small gaps than in medium ones (Fig. 6) with significant difference between the gap centres, but not between the gap edges. Among the possible reasons Grassi \& Bagnaresi (2001) consider that the limited ability of silver fir to exploit high-light conditions, limits its recruitment to small gaps. No significant difference of seedling density was observed between gap centres and gap edges inside the small gaps while it was significant in medium gaps (Fig. 6).

Silver fir seedling density tended to be were recorded also in the eastern positions (Fig. 7). This confirms that the natural regeneration of a shade-tolerant species, as silver fir, seems to occur in those sectors of the gap receiving less PAR but sufficient to allow the seedlings growth. Indeed the distribution patterns of seedlings of shade-tolerant tree species, in northern hemisphere, follow the shady southern edges of gaps, as demonstrated by Gray \& Spies (1996) in the Cascade Mountains (USA) where regeneration of shade-tolerant species was more abundant in shaded portions of gaps. In the northwestern British Columbia (Canada) Abies lasiocarpa and Abies amabilis "appeared to regenerate equally well at all gap positions but showed a clear preference for shadier small and medium sized gap" (Coates 2002). Diaci (2002) for a mixed forest with beech, silver fir and Norway spruce, in a Pre-alpine region of Slovenia, reported that the northern edges of the gaps can be unfavourable for germination since direct solar radiation, low precipitations and root competition occur. These results are in accordance with Ciancio et al. (1985) reporting the occurrence of natural regeneration in the centre of natural small gaps in silver fir stands of the same area of this study. However, contrasting results were obtained by Mercurio $(1994,2000)$ in exper-
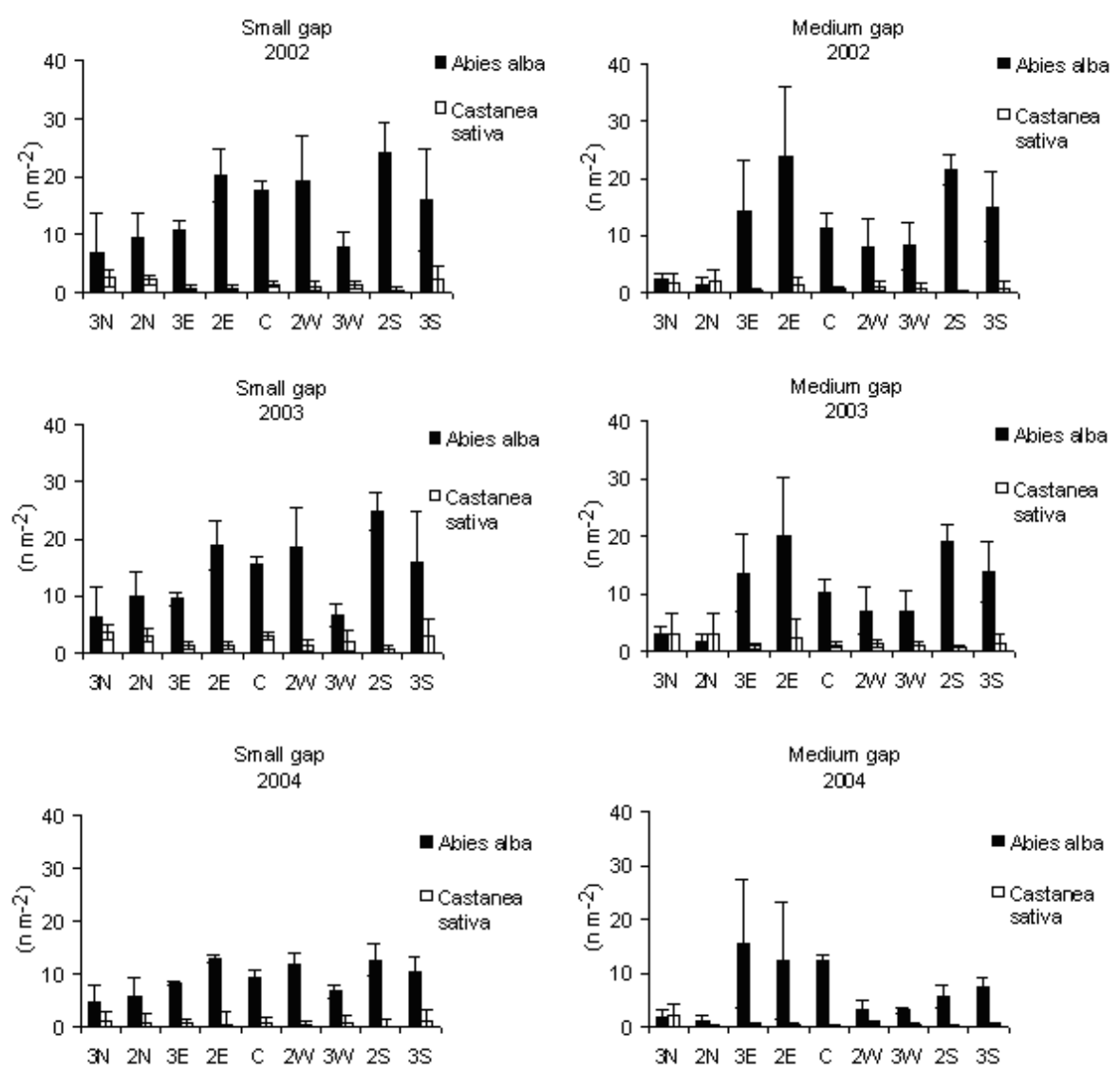

Fig. 7 - Distribution of seedling density according to within-gap position. The vertical bars represent standard errors. 

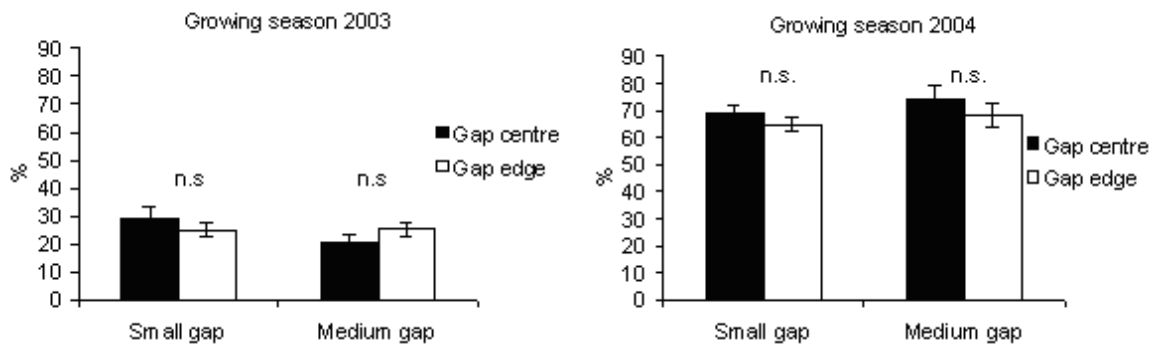

Fig. 8 - Seedlings mortality (2003-2004) according to gap sizes and within-gap position. The vertical bars represent standard errors.
Seedlings growth 2003

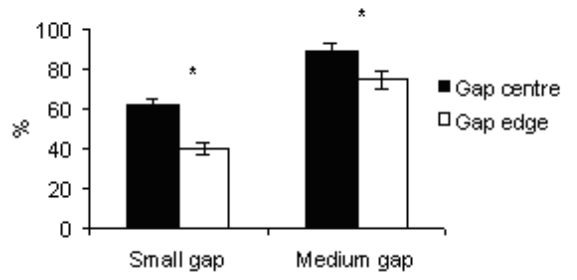

Seedlings growth 2004

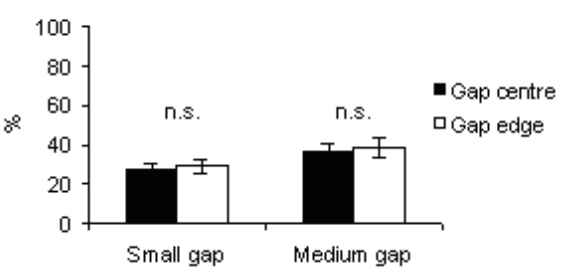

Fig. 9 - Seedlings height increment according to gap sizes. The vertical bars represent standard errors.

imental gaps of artificial stands in the Central Apennine (Italy) in which fir regeneration was concentrated to the gap edges. This could suggest a diverse ecological behaviour of silver fir of Serra San Bruno.

\section{Seedling mortality}

After three growing seasons seedling mortality was higher in the gap centres, but with no significant differences between gap sizes and within-gap positions (Fig. 8). The increase (about $40 \%$ ) in seedling mortality, between 2003 and 2004, could be partially related to the detrimental effect of ground vegetation for natural regeneration (Diaci 2002, Paluch 2005). In small gaps the vegetation cover (68\%) was $30 \%$ lower than that of medium gaps (96\%) and was negligible at the edges. This could have influenced the higher values of seedling mortality in medium gaps than in the small ones.

\section{Seedling growth}

In 2003, the percentage of seedling height increments (Fig. 9) was significantly higher

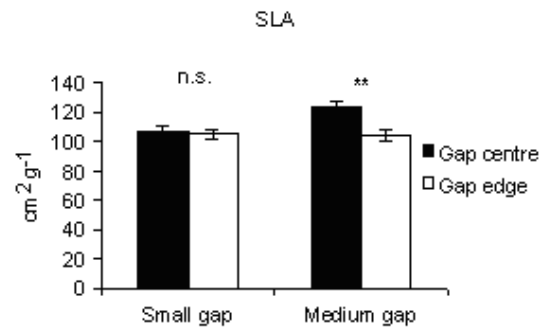

Fig. 10 - Means ( \pm s.e.) of Specific Leaf Area (2004) in gap centres of medium gaps where PAR transmittance was higher. This is in accordance with Gray \& Spies (Gray \& Spies 1996, Gray \& Spies 1997): seedling size increased with gap size and was greater at gap centres. In northern temperate forest of British Columbia (Canada), after five years, growth of planted seedlings of shade tolerant and intolerant species increased rapidly from small single-tree gaps to about $1000 \mathrm{~m}^{2}$ gaps thereafter showed little change in gaps up to 5000 $\mathrm{m}^{2}$ (Coates 2000).

Reduced seedling growth in response to decreased light availability has been found in a variety of forest types (Brown 1996, Drobyshev \& Nihlgard 2000, McGuire et al. 2001, Hunziker \& Brang 2005). Indeed, in 2004, the percentage of seedling height increment (Fig. 9) and was higher in gap edges than in gap centres. A probable reason could be that in the gap edges the shading influence of ground vegetation was less relevant than in the gap centres as observed by Mercurio (Mercurio 1994, Mercurio 2000) in artificial gaps in silver fir stands in the Central Apennine (Italy). Also Diaci (2002) refers about the importance of these ground vegetationfree microsites for the establishment of silver fir regeneration.

\section{Specific leaf area}

Specific leaf area (SLA) was used as an indicator of above-ground limitations on foliage growth and development arising from understory shading. In 2004, it was significantly higher at centres than at edges at medium gaps (Fig. 10), meaning that in the decreased with respect to 2003 in all gaps centres the foliage suffers from shading limitations of ground vegetation cover. On the other hand in A. alba total seedling biomass and total leaf area respond positively to increasing irradiance (Robakowski et al. 2004).

\section{Conclusions}

It is often advocated that ecologically sound silvicultural systems should be based on natural forest processes in order to obtain stable and self-sustaining forest systems (Attiwill 1994, Coates \& Burton 1997, Führer 2000). The gap-based approach and the gapcutting system (sensu Coates \& Burton 1997, Van Der Meer et al. 1999) simulate smallscale disturbances like natural gaps and are able to support the above mentioned purposes. This study shows that silver fir seedlings recruitment was greater in small gaps and in the central-southern positions. The most suitable gap size (expanded gap, sensu Runkle 1982) for silver fir regeneration, in this studied area, is $200(300) \mathrm{m}^{2}, \mathrm{D} / \mathrm{H}=0.5$ and anyway $<0.75$. As also supported by Ciancio et al. (1985) who indicate for silver fir stands of the Calabrian Apennine a gap size of $200-400 \mathrm{~m}^{2}$ with a $\mathrm{D} / \mathrm{H}$ ratios $<0.75$. In order to foster seedling growth, browsing pressure by domestic cows needs to be controlled as well as, in the first years, the shrub/herb layer. The silvicultural treatment proposed may promote natural regeneration of silver fir and other broadleaves, enhance the development of a multi-layered forest structure and meet timber production objectives without compromising ecosystem management principles.

\section{Acknowledgments}

This study was supported with funds by Regione Calabria within the project "The renaturalisation of conifer plantations". We thank Dr. Antonio Poletto from Azienda Agricola S. Maria for logistical support.

\section{References}

Attiwill PM (1994). The disturbance of forest ecosystems: the ecological basis for conservative management. Forest Ecology and Management 63: 247-300.

Barbagallo C, Brullo S, Furnari S, Longhitano N, Signorello P (1982). Studio fitosociologico e cartografia della vegetazione $(1: 25000)$ del territorio di Serra S. Bruno (Calabria). CNR, Collana del $\mathrm{PF}$ "Promozione della qualità dell'ambiente", $\mathrm{AQ} / 1 / 227$, Roma.

Brokaw NVL, Scheiner SM (1989). Species composition in gaps and structure of a tropical forest. Ecology 70 (3): 538-541.

Brown N (1996). A gradient of seedling growth from the centre of a tropical rain forest canopy gap. Forest Ecology and Management 82: 239244.

Busing RT, White PS (1997). Species diversity and small-scale disturbance in an old-growth 
temperate forest: a consideration of gap partitioning concepts. Oikos 78: 562-568.

Canham CD, Denslow JS, Platt WJ, Runkle JR, Spies TA, White PS (1990). Light regimes beneath close canopies and tree-fall gaps in temperate and tropical forests. Can. J. For. Res. 20: 620631.

Ciancio O, Iovino F, Menguzzato G, Mirabella A (1985). L'abete (Abies alba Mill.) in Calabria: possibilità e limiti di diffusione e ridiffusione. Annali Istituto Sperimentale per la Selvicoltura Vol. XVI: 5-249.

Coates KD (2000). Conifer seedling response to northern temperate forest gaps. Forest Ecology and Management 127: 249-269.

Coates KD (2002). Tree recruitment in gaps of various size, clearcuts and undisturbed mixed forest of interior of British Columbia (Canada). Forest Ecology and Management 155: 387-398.

Coates KD, Burton PJ (1997). A gap-based approach for development of silvicultural systems to address ecosystem management objectives. Forest Ecology and Management 99: 337-354.

Cutini A, Gamba C, Mercurio R, Modica G, Piovanelli C, Simoncini S (2004). Osservazioni ecologiche su tagli a buche nelle abetine del Parco Nazionale delle Foreste Casentinesi. Annali Istituto Sperimentale per la Selvicoltura Vol. XXXI (2000): 27-38.

Diaci J (2002). Regeneration dynamics in a Norway spruce plantation on silver fir-beech forest site in the Slovenian Alps. Forest Ecology and Management 161: 27-38

Denslow JS (1987). Tropical rainforest gaps and tree species diversity. Annual Review of Ecology and Systematics 18: 431-451.

Drobyshev I, Nihlgard B (2000). Growth response of spruce saplings in relation to climatic conditions along a gradient of gap size. Can. J. For. Res. 30: 930-938.

Fenner M (1985). Seed Ecology. Chapman \& Hall, London.

Führer E (2000). Forest functions, ecosystem stability and management. Forest Ecology and Management 132: 29-38.

Gagnon JL, Jokela EJ, Moser WK, Huber DA (2003). Dynamics of artificial regeneration in gaps within a longleaf pine flatwoods ecosystem. Forest Ecology and Management 172: 133-144.

Grassi G, Bagnaresi U (2001). Foliar morphological and physiological plasticity in Picea abies and Abies alba saplings along a natural light gradient. Tree Physiology 21: 959-967.

Gray AN, Spies TA (1996). Gap size, within-gap position and canopy structure effects on conifer seedling establishment. Journal of Ecology 84: 635-645.

Gray AN, Spies TA (1997). Microsite controls on tree seedling establishment in conifer forest canopy gaps. Ecology 78: 2458-2473.

Gray AN, Spies TA, Easter M.J (2002). Microclimatic and soil moisture responses to gap formation in coastal Douglas-fir forests. Can. J. For. Res. 32: 332-343.

Hunziker U, Brang P (2005). Microsite patterns of conifer seedling establishment and growth in a mixed stand in the southern Alps. Forest Ecology and Management 210: 67-79.

Lieffers VJ, Messier C, Stadt KJ, Gendron F, Comeau PG (1999). Predicting and managing light in the understory of boreal forests. Can. J. For. Res. 29: 796-811.

Livingston NJ, Black TA (1988). The growth and water use of three species of conifer seedlings planted on a high elevation south-facing clearcut. Can. J. For. Res. 18: 1234-1242.

Magini E (1967). Ricerche sui fattori della rinnovazione naturale dell'abete bianco sull'Appennino. L'Italia Forestale e Montana 22 (6): 261270.

Malcom DC, Mason WL, Clarke GC (2001). The transformation of conifer forests in Britain - regeneration, gap size and silvicultural systems. Forest Ecology and Management 151: 7-23.

McGuire JP, Mitchell RJ, Moser EB, Pecot SD, Gjerstad DH, Hedman CW (2001). Gaps in a gappy forest: plant resources, longleaf pine regeneration, and understory response to tree removal in longleaf pine savannas. Can. J. For. Res. 31: 765-778.

Mercurio R (1994). Esperienze sul trattamento delle abetine nelle foreste casentinesi. Annali Istituto Sperimentale per la Selvicoltura Vol. XXII (1991): 95-116.

Mercurio R (2000). Esperienze e prospettive sull'applicazione del taglio a buche nelle abetine del Parco Nazionale delle Foreste Casentinesi. L'Italia Forestale e Montana, 55 (4): 219-230.

O'Hara KL (2001). The silviculture of transformation - a commentary. Forest Ecology and Management 151: 81-86.

Paci M (2004). Ecologia Forestale. Edagricole.

Paluch JW (2005). The influence of the spatial pattern of trees on forest floor vegetation and sil- ver fir (Abies alba Mill.) regeneration in unevenaged forests. Forest Ecology and Management 205: 283-298.

Pickett STA, White PS (1985). The Ecology of Natural Disturbance and Patch Dynamics. Academic Press, New York.

Pierce LJ, Running SW (1988). Rapid estimation of coniferous forest leaf area index using portable integrating radiometer. Ecology 69 (6): 1762-1767.

Platt WJ, Strong DR (1989). Special feature. Gaps in forest ecology. Ecology 70: 535-575.

Poulson TL, Platt WJ (1989). Gap light regimes influence canopy tree diversity. Ecology 70: 553555.

Runkle JR (1982). Patterns of disturbances in some old-growth mesic forests of eastern North America. Ecology 63: 1533-1546.

Ritter E, Dalsgaard L, Einhorn KS (2005). Light, temperature and soil moisture regimes following gap formation in a semi-natural beech-dominated forest in Denmark. Forest Ecology and Management 206: 15-33.

Robakowski P, Wyka T, Samardakiewicz S, Kierzkowki D (2004). Growth, photosynthesis, and needle structure of silver fir (Abies alba Mill.) seedlings under different canopies. Forest Ecology and Management 201: 211-227.

Van Der Meer PJ, Dignan P, Savenh AG (1999). Effect of gap size on seedling establishment, growth and survival at three years in mountain ash (Eucalyptus regnans F. Muell.) forest in Victoria, Australia. Forest Ecology and Management 117: 33-42.

USDA-NRCS (1998). Keys of Soil Taxonomy. Eight Edition. USDA.

Watt AS (1947). Pattern and process in the plant community. Journal of Ecology 35: 1-22.

Whitmore TC (1989). Canopy gaps and the two major groups of forest trees. Ecology 70: 536538.

Zhu J, Matsuzaki T, Lee F, Gonda Y (2003). Effect of gap size created by thinning on seedling emergency, survival and establishment in a coastal pine forest. Forest Ecology and Management 182: 339-354.

Zirlewagen D, von Wilpert K (2001). Modelling water and ion fluxes in a highly structured, mixed-species stand. Forest Ecology and Management 143: 27-37. 